\title{
PROPOSTA DE IMPLEMENTAÇAO DE PROGRAMA ESTRUTURADO DE QUALIFICAÇÃO DOS FORNECEDORES DE CERVEJARIA ARTESANAL
}

\section{ARTIGO ORIGINAL}

AMORIM, Ingrid Falcão De ${ }^{1}$

SOUZA, Bárbara Cardoso de ${ }^{2}$

ARAÚJO, Leonardo Aquino de ${ }^{3}$

SILVA, Marco Antônio da Silva e ${ }^{4}$

ROBERTO, Jose Carlos Alves ${ }^{5}$

AMORIM, Ingrid Falcão De. Et al. Proposta de implementaçao de programa estruturado de qualificação dos fornecedores de cervejaria artesanal. Revista Científica Multidisciplinar Núcleo do Conhecimento. Ano 05, Ed. 11, Vol. 23, pp. 3660. Novembro de 2020. ISSN: 2448-0959, Link de acesso:https://www.nucleodoconhecimento.com.br/administracao/programaestruturado

\section{RESUMO}

As indústrias para obterem melhores qualidades em seus produtos e mercadorias precisam de fornecedores que propicie matéria prima de excelência, preços baixos, praticidade, menor tempo de entrega, entre outros serviços. Assim acontece com as

\footnotetext{
${ }^{1}$ Graduanda em Administração.

2 Graduanda em Administração.

${ }^{3}$ Graduanda em Administração.

${ }^{4}$ Graduanda em Administração.

${ }^{5}$ Orientador. Mestre em Engenharia de Produção.
} 
empresas de cervejaria artesanal. Nessa perspectiva o referido artigo tem por objetivo argumentar sobre a importância do processo de qualificação de fornecedores, bem como identificar melhores práticas que se adequam ao mercado de cerveja artesanal e por fim esquematizar estratégia de qualificação de fornecedores. Como metodologia aplicou-se pesquisa de natureza aplicada, descritiva, qualitativa e bibliográfica que possibilitou embasar, argumentar e analisar o tema pesquisado. Assim, teve como resultado a proposta de estratégia de qualificação de fornecedores para as empresas de cervejas artesanais do Amazonas.

Palavras-chaves: Fornecedor, qualificação, estratégias.

\section{INTRODUÇÃO}

As empresas de cervejas artesanais para manterem-se no mercado, precisam oferecer aos seus clientes cervejas de qualidade. Para que isso ocorra, a qualidade inicia-se na aquisição de matéria prima. Dai a importância da qualificação de fornecedores de matéria prima, entre outros materiais de insumos que atenda interesse e exigências dessas empresas.

Como o mercado de cerveja artesanal no Amazonas vem se desenvolvendo, considera-se uma problemática a qualificação de fornecedores.

Assim, surgiu o interesse de pesquisa, tendo como tema Proposta de Implementação do processo de qualificação de fornecedores por considerar o assunto relevante para essas empresas.

O referido artigo tem como objetivo geral argumentar sobre a importância do processo de qualificação de fornecedores, tendo como objetivos específicos: Identificar a(s) melhor (es) práticas de qualificação de fornecedores utilizadas pelo mercado cervejeiro, com isso analisar quais dessas práticas melhores se adequam ao mercado de cerveja artesanal no Amazonas e esquematizar estratégia de qualificação de fornecedores para o seguimento mencionado. 
Para fins de pesquisa é contribuir para o crescimento das empresas de cerveja artesanal no estado do Amazonas.

A pesquisa abordou como metodologia a pesquisa de natureza descritiva, qualitativa e quanto aos meios de procedimentos de pesquisa foi bibliográfica e de campo que possibilitou embasar, argumentar e fazer análise sobre o tema.

Tendo como resultado esquema como proposta de estratégia de qualificação de fornecedores para otimização dos produtos das empresas de cervejas artesanais no Amazonas.

Assim, o presente artigo está organizado em: introdução, fundamentação teórica onde se descreve: $O$ surgimento da cerveja tradicional e, por conseguinte a cerveja artesanal, em sequência o Mercado Consumidor, Qualificação de Fornecedores, Estratégias adotadas pelas cervejarias, Metodologia, Análise e Discussão.

\section{RFERENCIAL BIBLIOGRÁFICO}

O Referencial Bibliográfico do referido artigo fundamentou-se a partir de material elaborado, como livros, publicações periódicas, artigos científicos, impressos diversos ou, ainda, textos extraídos da internet.

Assim o Referencial Bibliográfico segue organizado com: O surgimento da cerveja tradicional, O surgimento da cerveja artesanal, Mercado Consumidor, Qualificação de fornecedores.

\subsection{O SURGIMENTO DA CERVEJA TRADICIONAL}

Muitas são as histórias de origem da cerveja. Acredita-se que surgiu simultâneo com a agricultura, pois o cultivo de trigo é muito antigo assim como a cerveja. Segundo Colavitti e Pradini (2015) as escavações arqueológicas mostraram que a lavoura de cereais e a fabricação de cerveja sempre andaram juntas. 
Para Colavitti e Pradini (2015) há evidências que os povos da Suméria já faziam uso da bebida e por relacionar com a agricultura chamavam a cerveja na época de pão líquido.

Acredita-se que a cerveja tenha sido originada de maneira acidental, de certo modo, a fermentação de um cereal pode estar relacionada com agricultura e o preparo de pão, por isso nome dado à cerveja de pão líquido. (HORNSEY, 2003)

Segundo Colavitti e Pradini (2015) a cerveja que possui data de surgimento é Pilsner Urquell, que tem como data de fabricação 5 de outubro de 1842, na cidade de Pilsen, na Tchecoslováquia, feita pelo mestre cervejeiro Josef Groll.

No Brasil, pesquisas apontam que a primeira indústria de cerveja surgiu em 1842. E no ano de 1858, havia uma totalidade de seis fabricas de cervejas. (LIMBERGER, 2013)

Para Limberger (2013) o desenvolvimento do setor de cerveja no Brasil se deve à colonização europeia em meados do século XIX, pois os colonizadores foram os primeiros a trazerem a indústria de cerveja para algumas cidades do país, como Rio de Janeiro, Rio Grande do Sul, Santa Catarina e Paraná. E no início do século XX havia aproximadamente 50 cervejarias no Brasil.

Entre os anos de 1860 e 1880 houve a descoberta de fermentação da cerveja, que segundo Hornsey (2003) foi chamado de anos de ouro da ciência cervejeira. As duas importantes descobertas para as cervejarias nessa época foram: A fórmula de

fermentação pelo químico francês Gay Lussac e da pasteurização pelo cientista Louis Pasteur.

Segundo Morado ( 2011) As descobertas da fórmula da fermentação pelo químico francês Gay Lussac e da pasteurização pelo cientista Louis Pasteur, proporcionaram um melhor entendimento do processo de fermentação, que a partir de então passou a ser um fator interessante para a diversificação da cerveja. Apesar de o nome de Pasteur ser popularmente associado ao processo de pasteurização do leite, na verdade suas pesquisas foram direcionadas à cerveja, como está 
registrado em seu documento Études sur la bière (Estudos sobre a cerveja), de 1876. Pasteur foi, durante muitos anos, consultor de várias cervejarias. (apud DELIBERALLI, p. 21,2015).

Assim, a descoberta de fermentação e pasteurização ocasionou diversidade de cervejas. E essa diversidade de cerveja se desenvolveu ao longo tempo, dando oportunidade para novos tipos de cerveja, como por exemplo a cerveja artesanal.

\subsection{O SURGIMENTO DA CERVEJA ARTESANAL}

A cerveja artesanal no Brasil surgiu ao mesmo tempo em que a cerveja comum foi desenvolvida, pois era feita de maneira rudimentar por volta do século XIX pelos imigrantes europeus, que produziam cerveja com alta fermentação. (LIMBERGER, 2013)

Entretanto, esse tipo de cerveja da época com alta fermentação perdeu espaço para as cervejas de baixa fermentação, preços baixos, entre outros fatores. Segundo Limberger (2013) com as técnicas de resfriamento que foram num total de 36 , o crescimento e desenvolvimento de transporte e urbanização, o comércio de cerveja se tornou mais vantajoso comprar cerveja em mercearias do que produzir.

Assim a cerveja artesanal ficou sendo feita de maneira familiar e no decorrer do século $\mathrm{XX}$, as cervejarias de pequeno porte perderam o mercado para as cervejarias maiores. (COUTINHO, 2014)

Para Giorgi (2015) no final do século XX, iniciou um fenômeno no Brasil relacionado ao mercado de cerveja que aconteceu nos Estados Unidos e partes da Europa. Tal fenômeno mudou o mercado da cerveja nacional que se deu em parte a percepção do cliente a respeito da bebida. Com isso, houve um crescimento de consumo de cerveja artesanal, favorecendo o aumento de produção e diversas cervejarias abriram.

Atualmente, o aumento de estabelecimento exclusivamente de venda de cerveja é considerável, tanto para a cerveja artesanal, como para cursos.

Ademais, pode ser observado um aumento considerável do número de estabelecimentos voltados exclusivamente à venda de cervejas tidas 
como especiais; de eventos de cerveja artesanal; assim como de cursos de formação de beer sommeliers; de degustação; de produção caseira, entre outros. (GIOGI, 2015)

A expectativa de crescimento e desenvolvimento da cerveja artesanal por parte dos produtores e consumidores é grande. E, para continuar essa expansão, os produtores e alguns clientes resolveram se unir e promover um movimento em prol da cerveja artesanal.

Tanto produtores como também consumidores e outras pessoas ligadas às cervejas artesanais estão promovendo um movimento em prol da disseminação da chamada "cultura cervejeira", cujo objetivo maior é ressignificar a bebida no Brasil, valorizando-a e celebrando-a em seus múltiplos aspectos (histórico, cultural, nutritivo, organoléptico, entre outros), e estabelecendo uma diferenciação entre o produto artesanal e o produto industrializado massificado. (GIOGI, 2015)

Para Delliberalli (2015) é importante ressaltar que as empresas de cervejarias artesanais, mostram-se apreensivos por conta da marca perante o consumidor, no que se refere à qualidade de tudo que engloba a cerveja artesanal.

Urdan (2010) citado por Delliveralli (2015) a qualidade do produto se relaciona aos atributos intrínsecos do objeto, que no caso das cervejas é resultado da escolha de matérias-primas superiores e métodos de produção que seguem padrões muitas vezes seculares em sua fabricação.

Nesse sentido, as cervejarias devem ter uma organização estruturada, nas questões de escolha de matéria prima, como também de materiais insumos, entre outros.

Consequentemente com produto de qualidade no mercado as empresas alcançarão seus objetivos no que se refere à venda de seus produtos por conta da grande aquisição.

\subsection{MERCADO CONSUMIDOR}

O mercado consumidor de cerveja artesanal tem se desenvolvido nos últimos anos. Segundo Serviço Brasileiro de Apoio às Micro e Pequenas Empresas-SEBRAE 
(2019) o segmento de cerveja cresceu $23 \%$ em 2018 , com isso o Brasil tornou-se o terceiro país produtor de cerveja artesanal do mundo.

As cervejarias artesanais estão em diversos estados do Brasil, e, os consumidores estão mais exigentes. Com isso buscam por cervejas artesanais com novos sabores e aromas.

O alto consumo deve-se em parte às mudanças de comportamento dos consumidores. Para Sampaio (2003) é perceptível modificações no mercado mundial e principalmente no Brasil, devido aumento da concorrência e principalmente à mudança de comportamento do consumidor.

Os consumidores estão mais exigentes. Segundo Sampaio (2003) os consumidores estão mais sofisticados, seletivos no que se refere ao consumo e ateísta à propaganda e ao marketing tradicional.

Para Perez (2008) A ebulição do mercado de cervejas artesanais se relaciona ao surgimento crescente de consumidores mais exigentes. $E$ afirma que o acesso às informações, tornam os consumidores mais atentos aos produtos e adeptos a customização e criatividade que as cervejas artesanais proporcionam.

Segundo Fonte Infomoney (2019) citado pelo SEBRAE (2019) aponta aumento de consumo da cerveja artesanal devido o sabor diferenciado, cerca de $12 \%$ de pessoas consomem com frequência e $53 \%$ beberam algumas vezes.

\subsection{QUALIFICAÇÃO DE FORNECEDORES}

Segundo Bueno (2003) citado por Cavalcanti e Santin (2004, p.46) por volta da década de 80, a International Organization for Standardization (ISO) iniciou a elaboração da norma sistêmica para a qualidade. Essas normas são genéricas, não se limitava a um produto ou a um único setor, mas de uma avaliação do processo produtivo de modo geral. Essas normas foram denominadas série ISO 9000. 
Com mudanças no decorrer dos anos, os padrões em virtude das exigências por partes das empresas, clientes e consumidores aumentaram.

Desse modo, há necessidade de acompanhamento dessas mudanças no mercado, principalmente no que se refere aos fornecedores. Pois o desempenho de uma empresa tende a ser afetado por conta do desempenho de seus fornecedores,

Nesse cenário o processo de seleção e qualificação de fornecedores não pode ser de qualquer maneira. Para Sucupira (2003) citado por Cavalcanti e Santin (2004,

p.46) a qualificação de fornecedores não deve ser feito de maneira simples tendo como base apenas cadastros antigos, cartões de visita, entre outros. É preciso investigar a competência e as habilidades dos fornecedores nos aspectos produtivos, administrativos, financeiros e mercadológicos.

As sondagens investigativas devem feitas por funcionários das áreas técnicas e de compras realizando pesquisa com ferramentas que permitam tabulações práticas para eventuais comparações.

Avaliação do serviço prestado pelos fornecedores a seus clientes também deve ser obtida por meio de sinais evidentes.

\subsubsection{IMPORTÂNCIA DOS FORNECEDORES PARA AS EMPRESAS}

O fornecedor é de suma importância para o desenvolvimento de uma empresa, pois por meio do desempenho de suas funções, contribui significativamente para vantagens de competitividade no mercado.

Com vista em propiciar qualidade aos clientes, as empresas têm por expectativa adquirir mercadorias com preços baixos e de excelente qualidade. Assim é necessário encontrar fornecedor qualificado, comprometidos e que atendam os interesses das empresas, assegurando a qualidade do produto final. 
Para Moura (2009) é relevante que as empresam tenham critérios para a qualificação de fornecedores, como por exemplo, a reputação no mercado, entre outros. A qualificação deve ser em vista dos objetivos da empresa.

Para Macedo (2002) citado por Moura (2009, p.71) A qualificação de fornecedor tende favorecer o desenvolvimento das empresas, pois:

- Evita devoluções que possam incorrer em atrasos do início da produção;

- Evita não conformidades que possam ser detectadas nos processos da cadeia produtiva, ou somente no fim da linha, pelo cliente final, causando diferentes transtornos internos, o que pode afetar a imagem da empresa;

- Otimiza a rotina de fabricação de um produto;

- Pode reduzir o número de inspeções, otimizando o processo de recebimento;

- Esta em conformidade com requisitos normativos e

O desempenho do trabalho do fornecedor pode evitar para empresa maiores dificuldades, como por exemplo, atraso em entrega de mercadorias, problemas na produção do produto, entre outros.

\subsubsection{MELHORES PRÁtICAS PARA A QUALIFICAÇÃO DE FORNECEDORES}

Segundo Smith (1991) existe dois métodos para selecionar fornecedores: a licitação competitiva e a negociação. Nesse caso, o critério geralmente para seleção é o preço.

Para Wilson (1994) os critérios a serem aplicados na seleção de fornecedores são: Preço (critério econômico); qualidade (critério de desempenho); possibilidade de fornecer o produto (critério integrador); e possibilidade de entregar o produto (critério adaptativo).

Nessa expectativa os fornecedores devem possuir algumas características, como Baily et al. (2000) citado por Moura( 2009, p.71) lista algumas características de um bom fornecedor, sendo aquele que: 
- Cumpre prazos de entrega;

- Fornece itens com 'qualidade;

- Oferece preços competitivos;

- Tem um bom histórico de referências (de negócios);

- Fornece um bom serviço;

- Cumpre o prometido;

- Apoia tecnicamente (seus clientes)

A maneira de avaliar, qualificar e selecionar o fornecedor depende do objetivo de planejamento das empresas.

Para adquirir produtos sem maiores impactos no negócio da empresa, são utilizados métodos mais simples enquanto que produtos que afetam o negócio exigem métodos mais criteriosos.

Para Dobler e Burt (1996) citado por Moura (2009, p.74) A prática para qualificação de fornecedor pode ser por meio de avaliação da natureza, criticidade, complexidade, do valor e também do conhecimento acerca dos fornecedores potenciais.

Monczka et al. (1998) citado por Moura (2009, p.74), propõe modelo para avaliação e seleção de fornecedores.

Essa prática básica de avaliação pode ser identificada conforme a Figura 1 Atividade dp processo de avaliação e seleção de fornecedor. 
Identificar a necessidade de seleção de novo fornecedor
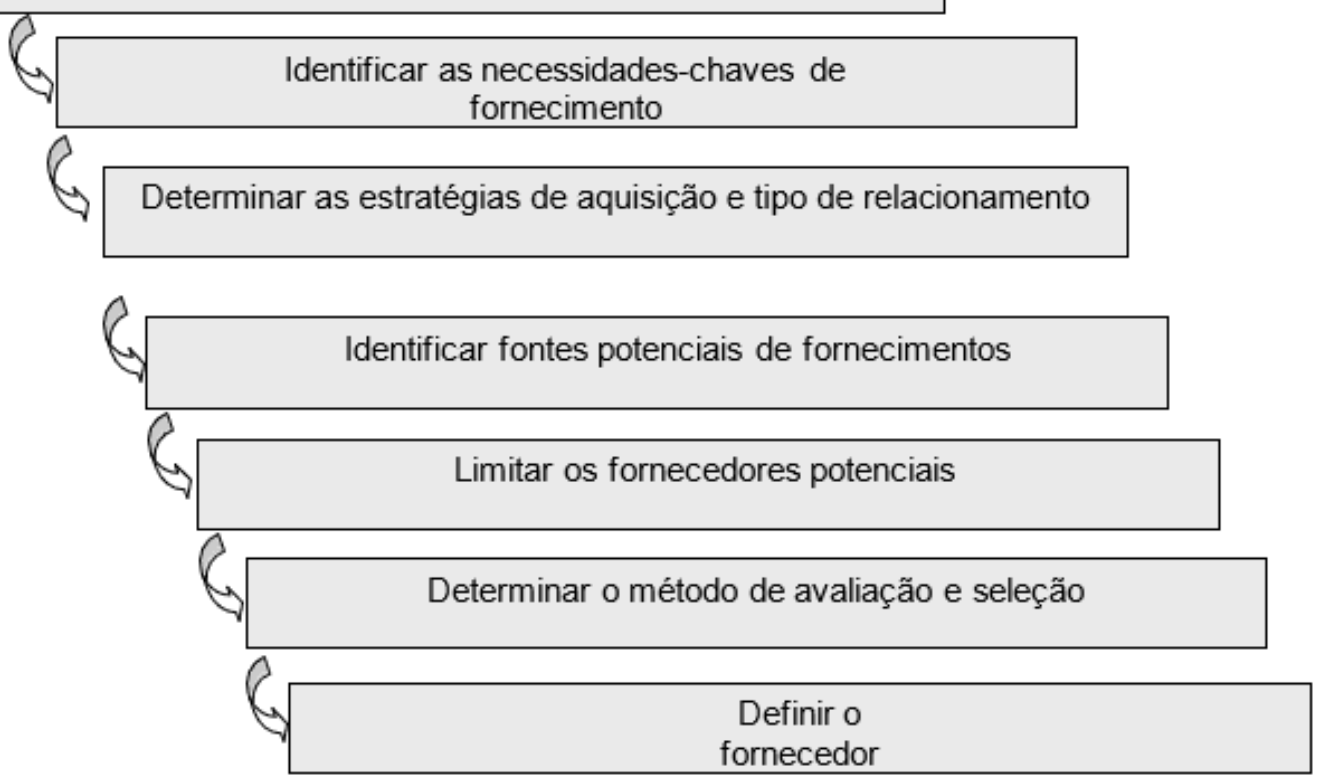

fornecedor

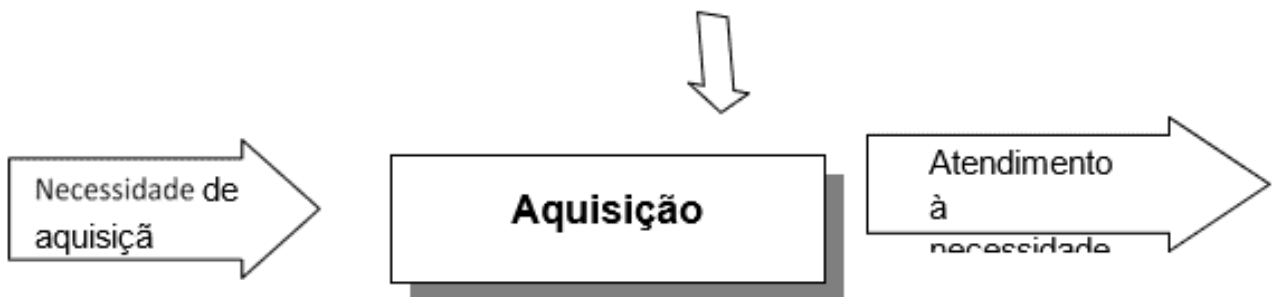

Figura 1 : Atividades do processo de avaliação e seleção de fornecedores - baseado em Monczka et al. (1998) citado por Moura (2009, p.74)

\subsubsection{ESTRATÉGIA DE QUALIFICAÇÃO DE FORNECEDORES}

Para empresa de qualquer ramo sugere-se: Selecionar fornecedores potenciais para fornecer matéria prima e insumos, o primeiro passo é encontrar e fazer a qualificação, e assim selecionar aquele fornecedor que atenda as expectativas da empresa. $O$ Jornal Contábil (2020) apresenta algumas estratégias que podem facilitar a encontrar fornecedores potenciais que melhor atenda os interesses da empresa, como por exemplo: 
- Procurar nos Polos em estados e cidade que são referência produtos e insumos;

- Frequentar feiras e congresso do setor especifico;

- Fazer visitas presenciais aos Polos ou empresas;

- Priorizar fornecedores locais. (JORNAL CONTABIL, 2020)

Uma vez encontrado o fornecedor é necessário ter critérios para a escolha de qual fornecedor melhor se enquadra com os objetivos da empresa.

\subsubsection{COMO ESCOLHER OS MELHORES FORNECEDORES}

Partindo do pressuposto que a empresa já tenha os nomes dos possíveis fornecedores, o próximo passo é a escolha, que pode ser analisada e avaliada pela a empresa dentre suas expectativas. Nesse sentido, é necessário filtrar aqueles que melhor se enquadram, para depois fechar negócio.

Assim, a empresa deve realizar sondagem a cerca do fornecedor, para verificar a reputação no mercado e na Junta Comercial ou ainda consultar O CNPJ do fornecedor.

Além disso, é importante considerar, qualidade dos produtos fornecidos, preço, prazo de entrega e a confiabilidade do fornecedor no mercado.

Qualidade: A matéria prima e o insumo, entre outros. Devem cumprir às especificidades técnicas requisitadas e ser disponível na quantidade correta e com boa qualidade, ou seja, não apresentando defeitos de fabricação e/ou outros problemas.

Preço: O valor de cada produto deve ser acessível. Sugere-se orçamentos com, no mínimo, três empresas para cada insumo, tendo assim mais opções de compra. Após analisadas condições disponibilizadas em cada oferta, escolha aquela que tenha melhor custobenefício.

Prazo de entrega: É de suma importância imprescindível o fornecedor possuir um bom sistema logístico, para que cada encomenda chegue ao seu tempo certo e sua produtividade não seja prejudicada. 
Confiabilidade dos fornecedores: É de suma importância à reputação dessas empresas no mercado e se a situação financeira está estável. Assim como, o relacionamento no que se refere ao bom atendimento de pós-venda com suporte eficiente, caso seja necessário trocar produtos ou realizar ajustes técnicos. (JORNAL CONTÁBIL, 2020)

Após esses critérios analisados, avaliados pela empresa é possível realizar a escolha do fornecedor para empresa de qualquer ramo de atividade.

\section{MATERIAIS E MÉTODOS}

Os materiais e métodos abordados no referido artigo possibilitou descrever, analisar e coletar informações para fundamentação da pesquisa. Com isso, proporcionou o processamento de informações para à resolução da problemática e questões de investigação. A pesquisa teve como objeto de estudo a Cervejaria Rio Negro, em virtude do desenvolvimento do mercado de cerveja artesanal no Amazonas buscouse resposta para a problemática em questão a qualificação de fornecedores. Nesse cenário segue os procedimentos metodológicos realizados no processo da pesquisa.

\section{1 PROCEDIMENTOS METODOLÓGICOS}

A metodologia é a sequencia de métodos e técnicas que serão utilizadas no decorrer da pesquisa.

A pesquisa corresponde a um conjunto de ações que deve seguir uma série de procedimentos previamente definidos através de um método baseado na racionalidade a fim de se encontrarem resultados e respostas a um problema previamente apresentado. (CARVALHO et al 2018 p.11)

Esses conjuntos de ações são decisões a serem tomadas. Para Kotler (2012) é necessário tomar decisões sobre fontes de dados para elaborar um plano de pesquisa, como instrumento de pesquisa, plano de amostragem, entre outros. Assim Os procedimentos metodológicos definidos para pesquisa e as regras gerais foram:

- QUANTO À NATUREZA 
Quanto à natureza utilizou-se a pesquisa qualitativa. Pois propiciou mais conhecimento a cerca de como investigar a problemática da pesquisa.

Numa pesquisa de cunho qualitativo, a interpretação do pesquisador apresenta uma importância fundamental. Afinal, não se trata apenas de um conjunto de informações fechadas cujo valor numérico é o único aspecto a ser levado em consideração, devido à própria natureza do fenômeno investigado. (CARVALHO et al 2018 p.29)

Optou-se pela pesquisa qualitativa por não descartar o conhecimento prévio. Com isso facilitou relacionar a subjetividade aos dados de pesquisa e consequentemente analisá-los para a solução do problema

\subsubsection{QUANTO AOS FINS}

Quanto aos fins utilizou-se a pesquisa descritiva, devido permitir-nos a registrar, analisar, classificar e interpretar o conteúdo da pesquisado. E de campo que nos possibilitou diagnóstico da empresa, com isso propiciou identificar a problemática e a solução para a mesma.

\subsubsection{QUANTOS AOS MEIOS}

Os meios utilizados na pesquisa foram Bibliográficos. A Pesquisa Bibliográfica Utiliza fontes bibliográficas ou material elaborado, como livros, publicações periódicas, artigos científicos, impressos diversos ou, ainda, textos extraídos da internet. (CARVALHO et al, 2019). Com isso, possibilitou fundamentar a pesquisa.

A pesquisa de Campo foi realizada na Cervejaria Rio Negro, onde foi feito pesquisa in loco o que nos propiciou o diagnóstico na empresa.

\subsection{CARACTERIZAÇÃO DA EMPRESA}

A Fabricação de Cervejas e Chopes Rio Negros LTDA, cujo nome fantasia é Deliriun. É uma empresa de pequeno porte, a empresa esta localizada na Rua Francisca Mendes, n 49, no bairro Cidade de Deus, Manaus - AM, 69099-345. A cervejaria Rio Negro é uma empresa genuinamente amazonense, que produz cervejas e chopes 
artesanais. Foi Criada em 2014, entrou em atividade somente em setembro de 2015, após total regularização junto aos órgãos de fiscalização (IPAAM, M.A.P.A., Corpo de Bombeiros, Prefeitura). Com isso a cervejaria vem trabalhando de uma forma regular e suas divulgações são por meio das redes sociais. O chope é produzido no endereço acima.

De acordo com os sócios proprietários Adelino da Silva (Administrador) e José Pereira de Lima (Sócio), o motivo que os levou ao empreendedorismo é a franca expansão do mercado de cervejas artesanais no país e o Amazonas. Situada na Zona Norte, o empreendimento se impõe pela estrutura externa que apresenta. Abriga equipamentos de tecnologia moderna que permita obter um produto de qualidade. Com a fabricação própria de cervejas artesanais, tem atualmente seis tipos de bebidas. Esses produtos são vendidos em mais de oitenta estabelecimentos na cidade de Manaus.

A empresa Rio Negro atualmente tem como objetivo de aumentar o quadro de colaboradores para obter seus resultados esperados, atualmente a empresa possui seis choperias e duas franquias na cidade com fabricações próprias e inovações de serviços de bar como, petiscos, pratos diferenciados regionais. busca todos os tipos de qualidades no que se refere a seus produtos, fidelizando o bem-estar de seus clientes, fabricando cervejas artesanais específicas e particulares de insumos regionais amazônicos. Objetivando os melhores aspectos qualitativos e visando o crescimento das vendas, com interesse de expansão e atuação no mercado nacional com suas novidades de cervejas, choperias artesanais de frutas regionais manauaras.

\section{- RESULTADOS E DISCUSSÕES}

As cervejas artesanais têm tido alto consumo no estado do Amazonas. Com isso a cervejaria Rio Negro precisa oferecer produto de qualidade para os clientes, que estão cada vez mais exigentes. Entretanto, conforme diagnóstico realizado na empresa observou-se baixo desempenho no que se refere à área de fornecedores. O que pode ser visto conforme Gráfico:1 abaixo:

Gráfico 1 - Média De Desempenho Por Área Funcional 


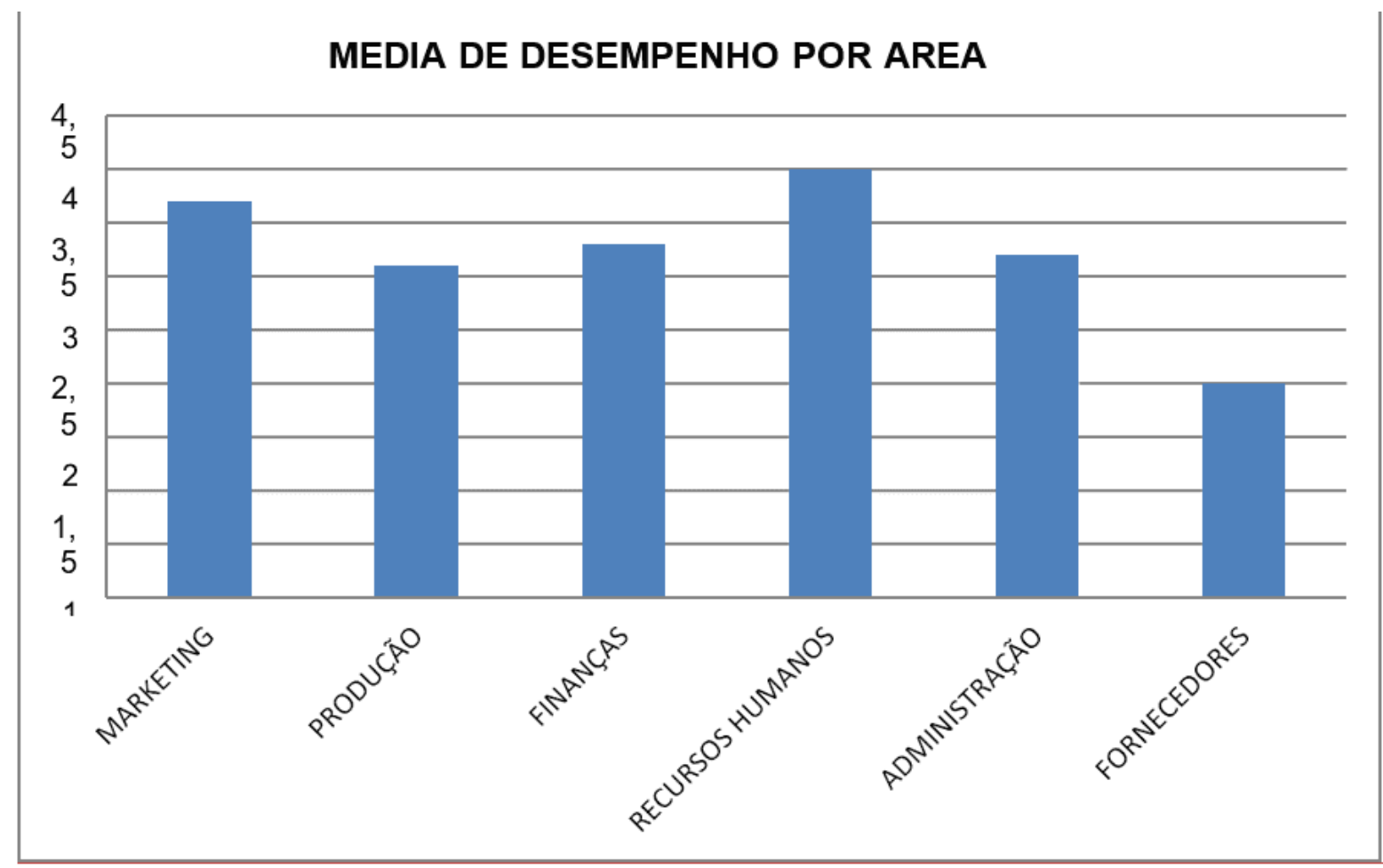

De acordo com o Gráfico 1, a área funcional mais crítica é a de fornecedores. Em vista de qualidade é necessário que a cervejaria artesanal Rio Negro obtenha de seus fornecedores os melhores produtos, tanto no que se refere à matéria prima como materiais de insumos. Em vista da área funcional mais crítica criou-se o quadro 1.Fonte: Elaborado pelos autores com base na pesquisa de campo. 2020

Quadro 1: Área Funcional Mais Crítica - Fornecedor

AREA FUNCIONAL

Fornecedor
NIVEL OU GRAU DE AVALIAÇÃO

\begin{tabular}{l|l|l|l|l|}
$\begin{array}{l}\text { Ponto } \\
\text { muito }\end{array}$ & & & & \\
forte & $\begin{array}{l}\text { Ponto } \\
\text { forte }\end{array}$ & $\begin{array}{l}\text { Ponto } \\
\text { médio }\end{array}$ & $\begin{array}{l}\text { Ponto } \\
\text { fraco }\end{array}$ & $\begin{array}{l}\text { Ponto } \\
\text { muito }\end{array}$ \\
\hline 5 & 4 & 3 & 2 & fraco \\
& & & & 1 \\
\hline
\end{tabular}




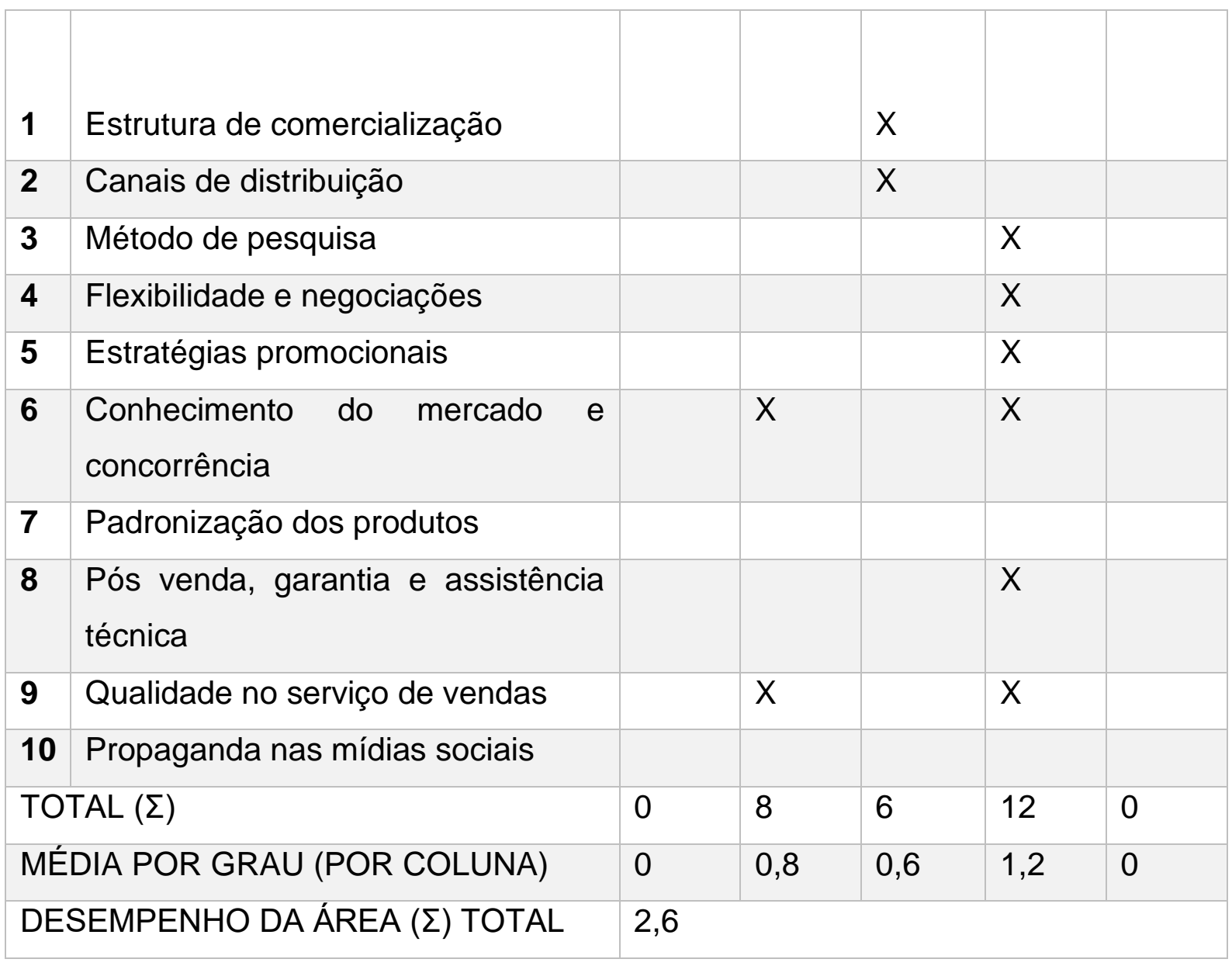

Fonte: Elaborado pelos autores com base na pesquisa de campo. 2020

As principais deficiências na área de fornecedor da cervejaria Rio Negro estão relacionadas à estrutura de comercialização, flexibilidade e negociações, estratégias promocionais, conhecimento do mercado e concorrência, pós venda, garantia e assistência técnica e qualidade no serviço de vendas.

Considerando área de fornecedor da empresa como deficiente e na oportunidade de melhoria de crescimento, qualidade de seus produtos e satisfação dos clientes e consumidores da cerveja artesanal Rio Negro. Foi desenvolvida uma proposta de melhoria.

Essa proposta de melhoria está indicando cinco pontos negativos e para cada ponto negativo uma ação de melhoria, no que se refere aos fornecedores na perspectiva 
que atendam os interesses da empresa, assegurando a qualidade do produto final. Abaixo Quadro 2 de proposta para melhoria da cerveja artesanal Rio Negro.

Quadro 2: Proposta De Melhoria

\begin{tabular}{|l|l|l|}
\hline & Pontos Negativos & Ações de melhorias \\
\hline $\mathbf{1}$ & $\begin{array}{l}\text { Auditoria para critérios d } \\
\text { e instalações e documentações }\end{array}$ & $\begin{array}{l}\text { Realizar auditoria para verificação geral } \\
\text { (instalação, documentação, etc) }\end{array}$ \\
\hline $\mathbf{2}$ & $\begin{array}{l}\text { Acompanhar o desenvolvimento } \\
\text { do fornecedor }\end{array}$ & $\begin{array}{l}\text { Verificar o cumprimento do combinado via } \\
\text { auditoria programada entre as partes. }\end{array}$ \\
\hline $\mathbf{3}$ & $\begin{array}{l}\text { Desenvolvimento de fornecedores } \\
\text { de acordo com a mudança no } \\
\text { mercado. }\end{array}$ & $\begin{array}{l}\text { Melhorar habilidades existentes no } \\
\text { fornecimento para atender os requisitos } \\
\text { das mudanças competitivas. }\end{array}$ \\
\hline $\begin{array}{l}\text { Avaliar e verificar se o fornecedor } \\
\text { mantém o bom fornecimento }\end{array}$ & $\begin{array}{l}\text { Qualificar por meio de critérios: prazo de } \\
\text { entrega, condições comerciais, entre } \\
\text { outros. }\end{array}$ \\
\hline $\mathbf{4}$ & $\begin{array}{l}\text { Estabelecer os processos, } \\
\text { estruturas e dispondo recursos } \\
\text { para o fornecimento. }\end{array}$ & $\begin{array}{l}\text { Organizar } \\
\text { e desenvolvimento de fornecedores }\end{array}$ \\
\hline & &
\end{tabular}

Fonte: Elaborado pelos autores com base na pesquisa de campo. 2020

Tendo em vista o Quadro 2 de ações de melhorias para a Cerveja Artesanal Rio Negro, o fornecedor desempenhará sua função com destreza, conhecimentos e práticas no mercado de fornecimento e propiciará desenvolvimento para a empresa. Realizando compras e negociações de produtos de qualidade de acordo com a 
necessidade do cliente. Possibilitando dessa forma, mais qualidade de produtos e preços baixos.

Nessa perspectiva de ações de melhoria, desenvolveu-se ações interventivas, que se deu de acordo com os pontos elencados no Quadro 2.

Para cada ponto negativo foi feito uma ação interventiva, apresentando o tempo estimado para a realização e conclusão da ação. Além do custo de cada ação.

Essa ação interventiva é de suma importância para a empresa, pois objetiva melhorar todos os itens críticos elencados no Quadro. Assim segue abaixo o Quadro 3 de Ações interventivas.

Quadro 3: Ações Interventivas

\begin{tabular}{|c|c|c|c|c|}
\hline Item & Ação Interventiva & Procedente & Cronologia & Custo \\
\hline 1. & $\begin{array}{l}\text { Realizar auditoria } \\
\text { para verificação geral } \\
\text { de instalações, } \\
\text { processos } \\
\text { documentações, } \\
\text { registros e adequação } \\
\text { de resultados. }\end{array}$ & $\begin{array}{l}\text { Redução ou } \\
\text { eliminações de } \\
\text { falsificações, } \\
\text { alterações, devoluções, } \\
\text { reprocesso. }\end{array}$ & cinco dias & $\begin{array}{l}R \$ \\
10.000,00\end{array}$ \\
\hline 2. & $\begin{array}{lr}\text { Monitorar } & \mathrm{e} \\
\text { acompanhar } & \mathrm{o} \\
\text { desenvolvimento } & \text { do } \\
\text { fornecedor. } & \end{array}$ & $\begin{array}{l}\text { Verificar se está } \\
\text { cumprindo o combinado } \\
\text { via auditoria } \\
\text { programadas entre as } \\
\text { partes. }\end{array}$ & quinze dias & $\mathrm{R} \$ 6.000,00$ \\
\hline 3. & $\begin{array}{l}\text { Exercer atividades } \\
\text { para } \\
\text { desenvolvimento de }\end{array}$ & $\begin{array}{l}\text { Melhoria das } \\
\text { habilidades existentes } \\
\text { no fornecimento para }\end{array}$ & seis dias & $\mathrm{R} \$ 3.000,00$ \\
\hline
\end{tabular}




\begin{tabular}{|c|c|c|c|c|}
\hline & $\begin{array}{ll}\text { fornecedores } & \text { de } \\
\text { acordo com a } & \\
\text { mudança } & \text { no } \\
\text { mercado. } & \end{array}$ & $\begin{array}{l}\text { atender os requisitos } \\
\text { das mudanças } \\
\text { competitivas. }\end{array}$ & & \\
\hline 4. & $\begin{array}{l}\text { Avaliar e verificar se o } \\
\text { fornecedor mantém o } \\
\text { bom fornecimento. }\end{array}$ & $\begin{array}{l}\text { Verificações de } \\
\text { atendimento a critérios } \\
\text { como conformidade, } \\
\text { prazo de entrega e } \\
\text { condições comerciais. }\end{array}$ & cinco dias & $\mathrm{R} \$ 7.000,00$ \\
\hline 5. & $\begin{array}{l}\text { Estabelecer os } \\
\text { processos, estruturas } \\
\text { e dispondo recursos } \\
\text { para o fornecimento. }\end{array}$ & $\begin{array}{l}\text { Organizar um programa } \\
\text { de desenvolvimento de } \\
\text { fornecedores. }\end{array}$ & Quatro dias & $R \$ 4.000,00$ \\
\hline \multicolumn{4}{|c|}{ TOTAL } & $\begin{array}{l}\mathrm{R} \$ \\
30.000,00\end{array}$ \\
\hline
\end{tabular}

Fonte: Elaborado pelos autores com base na pesquisa de campo. 2020

Conforme Quadro 3 de ações interventivas optou-se pela ferramenta de Gestão $5 \mathrm{~W} 2 \mathrm{H}$, e assim determinar detalhamento das ações.

A ferramenta $5 \mathrm{~W} 2 \mathrm{H}$ evidencia o planejamento de cada ação em virtude do problema, no que se refere à maneira de solucioná-lo, ou seja, é uma ação organizada, planejada detalhada, identificando, como será feito, tempo estimado, entre outros dando resposta aos questionamentos.

Assim, segue abaixo quadros de acordo com a ferramenta 5W2H.

Quadro 4: Problema 01 - Contratar Um Auditor Especializado 


\begin{tabular}{|c|c|c|}
\hline \multicolumn{2}{|c|}{ PERGUNTA } & DESCRIÇÃO \\
\hline WHAT & O que será feito? & $\begin{array}{l}\text { Realizar auditoria para verificação de } \\
\text { instalações e documentações. }\end{array}$ \\
\hline WHO & Quem fará? & Auditores terceirizados. \\
\hline WHERE & Onde será feito & Na própria empresa. \\
\hline WHEN & Quando fazer? & De imediato \\
\hline WHY & Por que será feito? & Para reduzir e eliminar falsificações \\
\hline HOW & Como fazer? & $\begin{array}{l}\text { Fazendo analise no mercado em busca do } \\
\text { profissional especializado. }\end{array}$ \\
\hline $\begin{array}{l}\mathrm{HOW} \\
\mathrm{MUCH}\end{array}$ & Quanto custa? & $\mathrm{R} \$ 10.000,00$ \\
\hline
\end{tabular}

Fonte: Elaborado pelos autores, 2020

Conforme quadro acima é necessário que a empresa faça a contratação de auditores para verificação de documentação e regularização de fornecedores. Esse profissional especializado fará na empresa uma auditoria na parte documental dos fornecedores. Com isso evitar falsificações e prejuízos judicial e financeiro para a cervejaria.

Assim segue quadros dando sequencia e evidenciando o planejamento detalhado de cada ação, como acompanhar desenvolvimento do fornecedor, capacitação, avaliação de fornecedor e organização de programa de desenvolvimento.

Quadro 5: Problema 02 - Acompanhar Desenvolvimento 


\begin{tabular}{|c|c|c|}
\hline PERGUI & & DESCRIÇÃO \\
\hline WHAT & O que será feito? & $\begin{array}{l}\text { Monitorar e acompanhar o desenvolvimento } \\
\text { do fornecedor. }\end{array}$ \\
\hline WHO & Quem fará? & Gerente \\
\hline WHERE & Onde será feito & Na própria empresa. \\
\hline WHEN & Quando fazer? & De imediato \\
\hline WHY & Por que será feito? & $\begin{array}{l}\text { Verificar se está cumprindo o combinado via } \\
\text { auditoria programada entre as partes. }\end{array}$ \\
\hline HOW & Como fazer? & Usando critérios de acordo com a empresa \\
\hline $\begin{array}{l}\mathrm{HOW} \\
\mathrm{MUCH}\end{array}$ & Quanto custa? & $R \$ 6.000,00$ \\
\hline
\end{tabular}

Fonte: Elaborado pelos autores, 2020.

Quadro 6: Problema 03 - Capacitação De Fornecedores

\begin{tabular}{|c|c|c|}
\hline \multicolumn{2}{|c|}{ PERGUNTA } & DESCRIÇÃO \\
\hline WHAT & O que será feito? & $\begin{array}{l}\text { Exercer atividades para o desenvolvimento } \\
\text { de fornecedores de acordo com a mudança } \\
\text { no mercado. }\end{array}$ \\
\hline WHO & Quem fará? & Gerente de capacitação terceirizado \\
\hline WHERE & Onde será feito & Na própria empresa. \\
\hline
\end{tabular}


\begin{tabular}{l|l} 
WHEN & Quando fazer?
\end{tabular}

\begin{tabular}{|l|l|l|}
\hline WHY & Por que será feito? & $\begin{array}{l}\text { Melhoria das habilidades existentes no } \\
\text { fornecimento para atender os requisitos } \\
\text { das mudanças competitivas }\end{array}$ \\
\hline HOW & Como fazer? & $\begin{array}{l}\text { Palestra de capacitação, incentivo e } \\
\text { atualidades do mercado cervejeiro. }\end{array}$ \\
\hline HOW & & \\
MUCH & Quanto custa? & $\mathrm{R} \$ 7.000,00$ \\
\hline
\end{tabular}

Fonte: Elaborado pelos autores, 2020.

A palestra de capacitação e incentivo colabora para o desenvolvimento do trabalho em equipe, favorecendo desempenho profissional e empresarial.

Quadro 7: Problema 04 - Avaliação De Fornecedores

\begin{tabular}{|l|l|l|}
\hline \multicolumn{2}{|l|}{ PERGUNTA } & $\begin{array}{l}\text { DESCRIÇÃO } \\
\text { Avaliar e verificar se o fornecedor mantém } \\
\text { o bom fornecimento }\end{array}$ \\
\hline WHAT & O que será feito? & Gerente de negócios: compra e venda \\
\hline WHO & Quem fará? & \\
\hline WHERE & Onde será feito & Na própria empresa. \\
\hline
\end{tabular}




\begin{tabular}{|c|c|c|}
\hline WHEN & Quando fazer? & De imediato \\
\hline WHY & Por que será feito? & $\begin{array}{l}\text { Qualificar o fornecedor por meio de } \\
\text { critérios: prazo de entrega, condições } \\
\text { comerciais, entre outros. }\end{array}$ \\
\hline HOW & Como fazer? & Utilizar estratégia de avaliação. \\
\hline $\begin{array}{l}\text { HOW } \\
\mathrm{MUCH}\end{array}$ & Quanto custa? & $R \$ 3.000,00$ \\
\hline
\end{tabular}

Fonte: Elaborado pelos autores, 2020.

A avaliação dos fornecedores é no sentido de competência, destreza, habilidade, bom relacionamento, entre outros critérios.

Quadro 8: Problema 05 - Oragnização De Programa De Desenvolvimento

\begin{tabular}{|l|l|l|}
\hline \multicolumn{2}{|l|}{ PERGUNTA } & DESCRIÇÃO \\
\hline WHAT & $\begin{array}{l}\text { Estabelecer os processos, estruturas e dis- } \\
\text { pondo recursos para o fornecimento. }\end{array}$ \\
\hline & O que será feito? & \\
\hline
\end{tabular}

\begin{tabular}{|l|l|l|}
\hline WHO & Quem fará? & $\begin{array}{l}\text { Profissional Especialista em organização } \\
\text { e programa de desenvolvimento. }\end{array}$ \\
\hline WHERE & Onde será feito & Na própria empresa. \\
\hline
\end{tabular}




\begin{tabular}{|l|l|l|}
\hline WHEN & Quando fazer? & De imediato \\
\hline WHY & Por que será feito? & $\begin{array}{l}\text { Organizar um programa de desenvolvimento } \\
\text { de fornecedores.. }\end{array}$ \\
\hline HOW & Como fazer? & $\begin{array}{l}\text { Fazendo analise no mercado em busca do } \\
\text { profissional }\end{array}$ \\
\hline HOW & Quanto custa? & $\mathrm{R} \$ 4.000,00$ \\
\hline
\end{tabular}

Fonte: Elaborado pelos autores, 2020.

Relacionando o quadro acima ao subtópico 2.4.2 foram identificadas as melhores práticas para a qualificação de fornecedor que são: Smit (1991) diz que há dois métodos, o de licitação e competitividade. Wilson (1994) prioriza os critérios: econômicos, desempenho e adaptativo. Dobler e Burt (1996) a qualificação se dá por meio da criticidade e complexidade, Monczka et al (1998) propõe modelo de avaliação e seleção de fornecedor. Todas essas práticas são maneiras de selecionar fornecedores potenciais e encontrar aquele que seja apto a fornecer produtos para a empresa. Diante da analise realizada em virtude da qualificação de fornecedor para cervejaria Rio Negro, sugere-se como proposta de intervenção, o fluxograma abaixo, na figura 2

Figura 2 : Fluxograma Da Proposta De Intervenção 


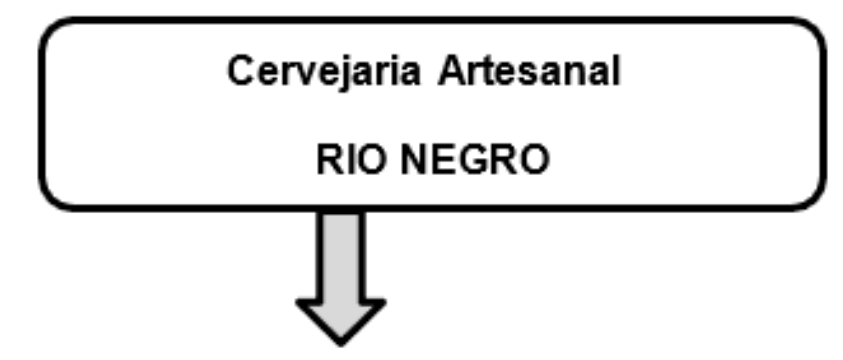

Fazer levantamento de possíveis fornecedores potenciais na região, feiras de negócios e em polos em outros estados.

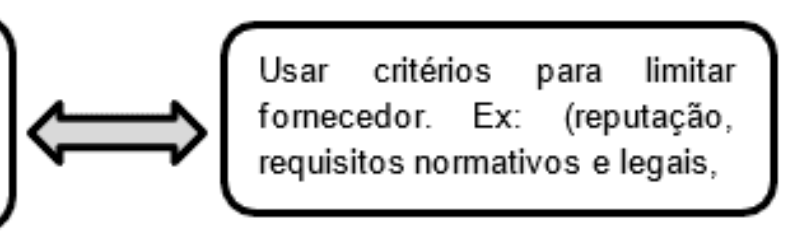

Limitar fornecedores potenciais.
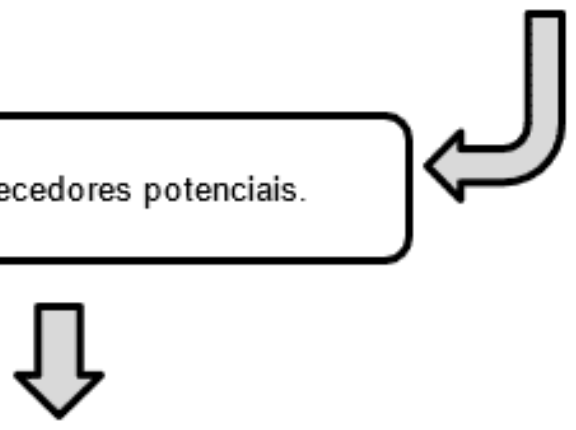

Usar critério para avaliar e selecionar fornecedor. Ex:

(qualidade de produto, preço, prazo, confiabilidade, etc.)

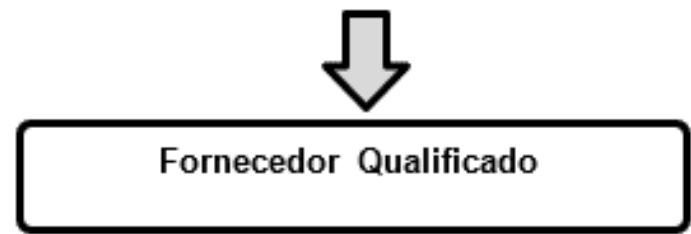

Fonte: os autores

\section{CONCLUSÃO}

O aumento do consumo de cervejas artesanais no estado do Amazonas tem aumentado muito nesses últimos anos. Com isso a preocupação das cervejarias é atender seus clientes com qualidade propiciando produtos de alta qualidade tendo em vista que atualmente os consumidores estão cada vez mais exigentes. 
Diante desse panorama cabe às cervejarias e a Cervejaria Rio Negro onde foi realizada a pesquisa, comprar mercadoria, como matéria prima e materiais de insumos de qualidade e principalmente com preços mais baixos. Além disso, outro fator importante deve ser levado em consideração, como por exemplo, a distância da Região.

Considerando o processo de compra e venda de produtos para as cervejarias artesanais do estado do Amazonas, o fornecedor tem um papel crucial para o desenvolvimento da empresa. Pois por meio do desenvolvimento do seu trabalho, consegue comprar produtos de alta qualidade e evita problemas que possam surgir no decorrer da compra até o termino do produto final.

Por isso, a cervejaria Rio Negro, deve utilizar estratégias para encontrar fornecedores com habilidades no comércio cervejeiro. Assim é importante que a cervejaria faça a qualificação de seus fornecedores, no sentido de selecionar aquele que melhor atenda suas expectativas.

Nesse sentido, é necessário que a cervejaria Rio Negro se apropriem de estratégias de onde encontrar fornecedores, como em feiras e polos, em seguida realizar a qualificação desses fornecedores a partir de critérios, como por exemplo, pesquisar a reputação do fornecedor, entre outros critérios que foram apresentados nesse referido artigo.

Assim, a cervejaria artesanal Rio Negro do estado do Amazonas terá mais credibilidade junto a seus clientes devido propiciar produtos de qualidade, por conta do fornecedor qualificado no exercido de sua função com habilidade, competência, aptidão, destreza e maestria.

\section{REFERÊNCIAS}

APCV. Associação Portuguesa dos Produtores de Cerveja. 2012 BELTRAMELLI, Mauricio. Cervejas, brejas e birras. 2.ed. São Paulo: Leya, 2014. CASCUDO, Luís da Camara. Prelúdio da cachaça. São Paulo: Global, 1962. 
BRASIL. Decreto - Lei ํo 8666 de 21 de junho de 1993 e Leis ํo 8883 de 8 de junho de 1994 e 9648 de 27 de maio de 1998. Ministério da Administração e Reforma do Estado. Brasília, DF. 1998.

CARVALHO, Luis Osete. El.al. Metodologia científica: teoria e aplicação na educação a distância / CARVALHO, Luis Osete Ribeiro. DUARTE, Francisco Ricardo. MENEZES, Afonso Henrique Novaes. SOUZA Tito Eugênio Santos [et al.]. Petrolina-PE, 2019. 83 p.: 20 cm. 1 Livro digital.

COLAVITTI Fernanda e PRANDINI Paula. O PRAZER de conhecer quem inventou a cerveja. História 150 anos e sempre gostosa. Disponível em: http://revistagalileu.globo.com/Galileu/0,6993,ECT625208-3029-3,00.html. Acesso dia 14 out.2020.

COMO encontrar e escolher bons fornecedores? Rede Jornal Contábil. MEI. Por Jornalismo

30 de abril de 2020. Disponível em: https://www.jornalcontabil.com.br/mei-como-encontrar-e-escolher-bonsfornecedores/ Acesso em 15 out 2020 .

DELIBERALLI, Camilo Camargo. Cervejas Artesanais no Brasil. Analise da Comunicação Integrada de Marketing da Cervejaria BODEBROWN. Universidade

Federal do Paraná Setor de Artes, Comunicação e Design - Sacod Departamento de Comunicação Social. 2015.

GIORGI, Victor Vargas. "Cultos em cerveja": discursos sobre a cerveja artesanal no Brasil. Mestrando em História . Universidade Federal de Uberlândia. Sociedade e Cultura, vol. 18, núm. 1, enero-junio, 2015, pp. 101-111 Universidade Federal de Goiás Goiania, Brasil.

HORNSEY, lan S. A History of Beer and Brewing. Cambridge: Royal Society of Chemistry, 2003. 
LAKATOS, Eva Maria. Fundamentos de metodologia científica 1. Marina de Andrade Marconi, Eva Maria Lakatos. - 5. ed. - São Paulo : Atlas 2003.

LIMBERGER, Silvia Cristina. O Setor Cervejeiro no Brasil: Gênese e Evolução. Caderno do Núcleo de Análises Urbanas Universidade Federal do Rio Grande FURG. Rio Grande/ RS. Vol. 6, 2013.

MOURA, LUCIANO RAIZER. Gestão do Relacionamento com Fornecedores. Análise da eficácia de programa para desenvolvimento e qualificação de fornecedores para grandes empresas. São Paulo, 2009.

OLIVEIRA, Marta Kohl; DANTAS, Heloysa. Teorias Psicogenéticas em discussão. SãoPaulo: Summus, 1992.

PEREZ Clotilde. Consumidores mais complexos e exigentes. Um desafio ético e estético para as marcas contemporâneas. E Gestão - Revista Eletrônica de Gestão e Negócios, jul-set/2008.

PRODANOV, Cleber Cristiano. Metodologia do trabalho científico [recurso eletrônico] : métodos e técnicas da pesquisa e do trabalho acadêmico / Cleber Cristiano Prodanov, Ernani Cesar de Freitas. - 2. ed. - Novo Hamburgo: Feevale, 2013.

SANTIN, Marta Regina\& CAVALCANTI, Osvaldo Albuquerque. Qualificação de fornecedores na indústria farmacêutica. Maringá/Paraná.Infarma, v.16, № 11-12, 2004.

SAMPAIO, Rafael. Propaganda de A a Z. Rio de Janeiro: Elsevier, 2003.

SMITH, R. C. Estimating and tendering for building work. London: Longman scientific and technical, 1991.

URDAN, F., T.; URDAN, A., T. O Impacto da Marca sobre as Preferências do Consumidor: Um Experimento com Cervejas. In: Encontro da Associação de Pesquisa e Pós Graduação em Administração (EnANPAD). Anais: 25o EnANPAD. 
Enviado: Outubro, 2020.

Aprovado: Novembro, 2020. 